\title{
Sistem Pakar Pemupukan Kelapa Sawit Menggunakan Metode Forward Chaining
}

\author{
Yusuf Priyandari $^{* 1)}$, Roni Zakaria $^{2)}$, Abdan Syakura ${ }^{3)}$ \\ ${ }^{1,2,3)}$ Teknik Industri, Fakultas Teknik, Universitas Sebelas Maret \\ J1. Ir. Sutami 36 A, Surakarta, 57126, Indonesia
}

\begin{abstract}
Oil palm smallholders require knowledge of fertilization because the fertilization is an influential factor in the productivity of fresh fruit bunches. On the other hand, the oil palm smallholders generally don't have fertilizer expertise and they face a difficulty in determining good fertilization (good in type, dosage, time and manner) based on various literatures. Therefore, a simple application that can provide recommendations for palm oil fertilization is developed. The recommendations are based on expert knowledge that have been written in various literatures. Like an expert system, the application is designed by compiling knowledge base, constructing an inference engine and creating a prototype. The knowledge bases, that are facts and rules, are prepared using rule-based reasoning approach, the inference engine is compiled using forward chaining methods and the prototype is made using a visual basic application in a spreadsheet application. The application design uses facts of plant varieties, phases or age of plants, soil types, nutrient deficiency in soil and plants, rainfall, fertilizer content, and nutrient properties (synergies or antagonist) on fertilizers. The Applications made capable of providing fertilization recommendations by conducting forward chaining based on data-given facts and rules that have been made on the knowledge base.
\end{abstract}

Keywords: Expert system, fertilizer recommendation, forward chaining methods, oil palm smallholders

\section{Pendahuluan}

Bentuk pengusahaan atau pengelolaan perkebunan kelapa sawit di Indonesia ada tiga bentuk yaitu perkebunan besar swasta (PBS), perkebunan besar negara (PBN), dan perkebunan rakyat (PR). Tahun 2014, luas lahan yang dikuasai ketiga perkebunan tersebut mencapai 10.754.801 Ha (Direktorat Jenderal Perkebunan, 2015). Adapun proporsi lahan perkebunan yang dikuasai secara berturut-turut adalah 51,62\%, 41,55\% dan 6,83\% untuk PBS, PR dan PBN (Ulum dan Hariyanto, 2015).

Pertumbuhan dan perkembangan kelapa sawit membutuhkan unsur-unsur hara makro dan mikro yang diperoleh dari tanah (Foth, 1994). Pada kasus unsur hara yang tersedia di tanah tidak mencukupi kebutuhan tanaman, maka unsur hara dapat dipenuhi melalui proses pemupukan (Sutejo dan Kartasapoetra, 1990). Pahan (2006) mengemukakan bahwa pemupukan adalah salah satu aktivitas dalam pengelolaan perkebunan kelapa sawit selain aktivitas lain seperti pembukaan lahan, pembibitan, penanaman, pengelolaan tajuk, perlindungan tanaman dan panen. Sejak awal pembibitan hingga berakhirnya masa produktif kelapa sawit selama lebih kurang dua puluh tahun, aktivitas pemupukan adalah aktivitas yang penting karena sangat mempengaruhi pertumbuhan vegetative dan produktivitas tandan buah segar (TBS) kelapa sawit (Salmiyati, et al., 2014). Pemupukan juga menjadi perhatian penting bagi pengelola perkebunan karena menurut Limbong (2011) bahwa porsi biaya pemupukan berkisar antara 40\%-60\% dari biaya pemeliharaan (pemupukan, penanggulangan hama dan penyakit, dan pemeliharaan tajuk).

Pemupukan yang baik harus tepat jenis, tepat dosis, tepat waktu dan tepat cara pemberian (4T) (Hidayat, 2012). Pemupukan yang baik perlu mempertimbangkan varietas tanaman, fase pertumbuhan dan umur tanaman, jenis tanah, defisiensi unsur hara pada tanah, curah hujan, dan sifat sinergis dan antagonis kandungan unsur hara yang terdapat pada pupuk (Pahan, 2006; Lubis, 2008; Allorerung et al., 2010, Firmansyah, 2010; Lumbangaol, 2011). Syakura et al, (2017) telah merangkum pengetahuan yang diperlukan dalam mengambil keputusan pemupukan kelapa sawit, khususnya untuk varietas Marihat.

Pengetahuan mengenai pemupukan yang baik untuk kelapa sawit perlu diketahui pengelola perkebunan, khususnya pengelola perkebunan rakyat. Namun demikian, pengetahuan pemupukan pada petani perkebunan rakyat umumnya masih terbatas karena cara berpikir petani diturunkan dari generasi tua ke generasi muda melalui proses sosialisasi sehingga tercipta model perilaku yang berorientasi pada sistem nilai dan diikuti patuh untuk jangka waktu lama meskipun situasi telah berubah (Planck, 1990). Padahal, pengetahuan baru

*Correspondance : priyandari@ft.uns.ac.id 
mengenai pemupukan yang baik, saat ini telah tersedia dalam berbagai literatur. Ketersediaan pengetahuan pemupukan pada literatur sebagai sumber sekunder, tidak memudahkan bagi petani perkebunan rakyat karena tidak ringkas untuk mengambil keputusan pelaksanaan pemupukan pada tiap-tiap area perkebunan yang memiliki kondisi berbeda-beda. Sebagai gambaran, referensi aturan pemupukan tanaman fase bibit pada Malangyoedo (2014), fase Tanaman Belum Menghasilkan (TBM) untuk jenis tanah gambut pada Allorerung el al., (2010), fase TBM untuk jenis tanah podsolik, alluvial dan entisol pada Firmansyah (2010), dan ada juga aturan-aturan pemupukan lainnya pada literatur Pahan (2006), dan Lumbangaol (2011). Adapun sumber primer yakni tenaga ahli, tidak selalu tersedia di perkebunan rakyat karena tenaga ahli berasal dari penyuluh pertanian pemerintahan.

Turban et al., (2007) mengatakan bahwa salah satu cara mentransfer pengetahuan dari tenaga ahli ke bukan ahli adalah menggunakan sistem pakar (expert system). Sistem pakar mengadopsi pengetahuan manusia ke komputer, agar komputer dapat menyelesaikan masalah seperti halnya yang bisa dilakukan oleh para pakar (ahli). Sistem pakar merupakan program knowledge engineering yang menyelesaikan permasalahan di dunia nyata yang bisa dilakukan oleh para ahli (Krishnamoorthy \& Rajeev, 1996). Sistem pakar mampu menyimpan pengetahuan yang jarang terjadi, menurunkan waktu pengambilan keputusan dan meningkatkan kualitas keputusan (Turban et al., 2007).

Kebutuhan pengetahuan tata cara pemupukan yang baik bagi petani perkebunan rakyat kelapa sawit, menjadi latar belakang diperlukannya sebuah aplikasi yang dapat membantu memberikan saran pelaksanaan pemupukan. Syakura et al., (2017) telah mengidentifikasi pengetahuan-pengetahuan yang diperlukan dalam pengambilan keputusan pemupukan. Oleh karena itu, aplikasi sederhana dikembangkan untuk mengimplementasikan basis pengetahuan yang telah disusun tersebut agar menjadi sebuah alat untuk memberikan rekomendasi pemupukan bagi petani perkebunan rakyat kelapa sawit.

\section{Metode Penelitian}

Sistem pakar mengadopsi pengetahuan manusia dan menyimpannya ke dalam komputer agar bisa membantu mengambil keputusan seperti yang dilakukan pakar (Redington, 1999; Turban et al., 2007). Sistem pakar memiliki komponen seperti basis pengetahuan (knowledge base), mekanisme pengambilan kesimpulan (inference mechanism), dan fasilitas penjelasan (explanation facility) yang saling berinteraksi dalam mensimulasikan pengambilan keputusan oleh pakar dalam bidang tertentu (Khrisnamoorthy dan Rajeev, 1996). Struktur sistem pakar terdiri dari dua bagian yaitu lingkungan pengembangan (development environment) dan lingkungan konsultasi (consultation environment) (Turban et al., 2007). Lingkungan pengembangan dilakukan atau dikerjakan oleh knowledge engineer untuk menghasilkan basis pengetahuan dan membuat mesin inferensi. Pada lingkungan konsultasi terdapat pengguna yang umumnya adalah bukan pakar yang menggunakan antar muka (interface) sistem pakar untuk berkonsultasi masalah dan mendapatkan suatu rekomendasi keputusan dari mesin inferensi yang telah dibuat pada lingkungan pengembangan.

Sejalan dengan konsep struktur sistem pakar, tahapan pengembangan aplikasi rekomendasi pemupukan kelapa sawit terdiri dari tiga bagian. Bagian pertama adalah identifikasi basis pengetahuan yang berupa fakta-fakta yang dibutuhkan untuk pemupukan kelapa sawit, dan pembuatan aturan yang merepresentasikan relasi antar fakta-fakta pengetahuan yang digunakan untuk menghasilkan sebuah keputusan pemupukan. Fakta-fakta untuk basis pengetahuan menggunakan pendapat tertulis (buku) sebagaimana dibolehkan oleh Urrea et al., (2015). Literatur yang digunakan adalah Malangyoedo (2014), Alloererung et al., (2010), Firmansyah (2010), Pahan (2006), dan Lumbangaol (2011). Rule based reasoning digunakan untuk merepresentasikan aturan pengetahuan, sehingga pengetahuan direkam menggunakan bentuk aturan JikaMaka (If-Then) untuk membantu menjawab pertanyaan yang dimasukkan (Rani et al., 2011).

Bagian kedua pengembangan aplikasi adalah membuat model keputusan dan mesin inferensi. Terdapat dua metode penalaran dalam mesin inferensi yaitu runut maju (forward chaining) dan runut mundur (backward chaining). Pada sistem pakar yang menggunakan rule based reasoning, digunakan metode penalaran runut maju (Yuhendra, 2008). Forward chaining merupakan pendekatan berbasis data, dimulai dari data yang tersedia sebagai ide dasar kemudian mencoba membuat kesimpulan. Turban et al., (2007) dan Arhami (2005) menyatakan bahwa forward chaining merupakan penalaran dari bawah ke atas karena penalaran dari fakta (evidence) pada level bawah menuju konklusi pada level atas didasarkan pada fakta. Penalaran runut maju ini akan menggunakan fakta input dan mencocokkan dengan aturan dalam basis pengetahuan untuk memberikan rekomendasi pemupukan.

Bagian ketiga adalah pembuatan antarmuka (interface). Antarmuka aplikasi dibuat menggunakan Visual Basic Application (VBA) yang terdapat pada aplikasi Microsoft Excel. Seluruh basis pengetahuan berupa 
fakta dan aturan disimpan di dalam kode program. Antarmuka hanya digunakan untuk menerima input fakta yang akan dikonsultasikan oleh pengguna bukan pakar untuk mendapatkan rekomendasi mengenai pemupukan.

\section{Hasil dan Pembahasan}

Berikut ini akan disampaikan hasil yang diperoleh dalam proses pengembangan aplikasi rekomendasi pemupukan kelapa sawit mulai dari basis pengetahuan, mesin inferensi dan antarmuka aplikasi.

\subsection{Basis Pengetahuan}

Basis pengetahuan pemupukan kelapa sawit yang berupa fakta dan aturan pemupukan telah diidentifikasi oleh Syakura et al., (2017). Basis pengetahuan secara umum yang telah diidentifikasi oleh Syakura et al., (2017) seperti disajikan pada Tabel 1. Ada tujuh domain pengetahuan yang digunakan dalam pengambilan keputusan rekomendasi pemupukan, yaitu varietas tanaman, fase tanaman, jenis tanah, defisiensi untur hara pada tanah atau pada tanaman, curah hujan, komposisi pupuk, dan sifat sinergis atau antagonis unsur hara dalam pupuk.

Tabel 1. Basis pengetahuan umum pemupukan kelapa sawit

\begin{tabular}{|c|c|c|c|}
\hline $\begin{array}{l}\text { Domain } \\
\text { Pengetahuan }\end{array}$ & Atribut & & Contoh Fakta Pengetahuan \\
\hline \multirow[t]{2}{*}{ Varietas } & Nama & $\overline{:}$ & Marihat \\
\hline & Karakteristik & : & $\begin{array}{ll}\text { - } & \text { Perawatan relatif lebih mudah } \\
\text { - } & \text { Ketahanan yang baik terhadap hama } \\
\text { - } & \text { Tonase Tandan Buah Segar (TBS) relatif lebih tinggi }\end{array}$ \\
\hline \multirow[t]{2}{*}{ Fase tanaman } & Nama & : & Tanaman Belum Menghasilkan (TBM) \\
\hline & Karakteristik & : & $\begin{array}{l}\text { Paska tanam sampai sekitar } 32 \text { bulan } \\
\text { Pada setiap fase (bulan) terdapat rekomendasi pemupukan }\end{array}$ \\
\hline \multirow[t]{2}{*}{ Umur tanaman } & Nama & : & TBM 8 - 12 bulan \\
\hline & Karakteristik & : & - \\
\hline Jenis tanah & $\begin{array}{l}\text { Nama } \\
\text { Karakteristik }\end{array}$ & $:$ & $\begin{array}{l}\text { Gambut } \\
\text { - } \quad \text { Keasaman tanah rendah } \\
\text { - } \quad \text { Kandungan hara tinggi } \\
\text { - } \quad \text { Tanah basah }\end{array}$ \\
\hline Defisiensi & Nama & : & Defisiensi unsur $P$ \\
\hline unsur hara & Karakteristik & : & $\begin{array}{l}\text { - Defisiensi tinggi jika hasil analisis tanah }<20 \mathrm{ppm} \text { (metode } \\
\text { Bray II), dan } \\
\text { - } \quad \text { analisis daun kurang dari } 0.15 \%\end{array}$ \\
\hline Curah hujan & $\begin{array}{l}\text { Nama } \\
\text { Karakteristik }\end{array}$ & $\begin{array}{l}: \\
:\end{array}$ & $\begin{array}{l}\text { Curah hujan rendah } \\
<60 \mathrm{~mm} / \text { bulan }\end{array}$ \\
\hline Pupuk & $\begin{array}{l}\text { Nama } \\
\text { Karakteristik }\end{array}$ & $\begin{array}{l}: \\
:\end{array}$ & $\begin{array}{l}\text { Ammonium sulphate }(\mathrm{ZA}) \\
-\quad \text { Kandungan unsur } \mathrm{N}=21 \% \\
-\quad \text { Kandungan unsur } \mathrm{S}=24 \%\end{array}$ \\
\hline $\begin{array}{l}\text { Sifat unsur pupuk } \\
\text { (Sinergis- } \\
\text { Antagonis) }\end{array}$ & $\begin{array}{l}\text { Nama } \\
\text { Karakteristik }\end{array}$ & $\begin{array}{l}: \\
:\end{array}$ & $\begin{array}{l}\text { Sinergis } \\
-\quad \text { Pupuk boleh dicampur } \\
-\quad \text { Pupuk boleh diaplikasikan dalam jangka waktu yang sama } \\
\quad \text { dan ditempat yang sama }\end{array}$ \\
\hline
\end{tabular}

Sumber : Syakura et al., (2017)

Aturan pemupukan menggunakan aturan jika-maka (if-then). Terdapat 209 aturan sebagaimana telah diidentifikasi oleh Syakura et al., (2017). Gambar 1 adalah contoh aturan ke-59. Pada aturan tersebut, fakta pengetahuan yang digunakan baru tiga domain pengetahuan yaitu varietas tanaman, jenis tanah, dan usia tanaman. Pada aturan tersebut pengetahuan lain tidak terlihat digunakan karena pengetahuan-pengetahuan lain akan digunakan sesuai model keputusan yang akan dijelaskan pada subbab selanjutnya. 


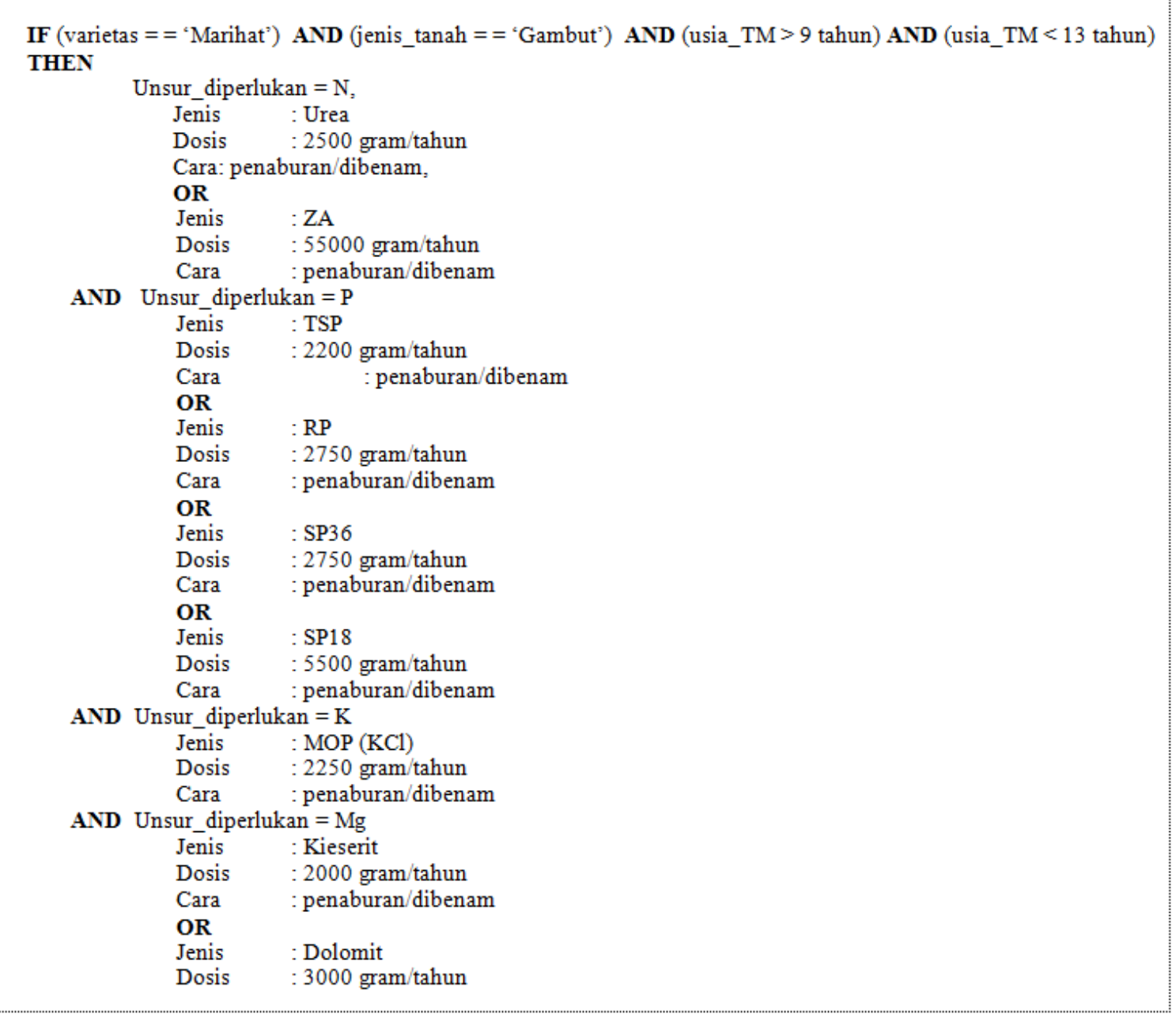

Gambar 1. Contoh aturan nomor 59 dalam basis pengetahuan pemupukan kelapa sawit Sumber : Syakura et al., (2017)

\subsection{Model Keputusan dan Mesin Inferensi}

Pengambilan keputusan menggunakan metode runut maju (forward chaining) sehingga fakta-fakta (evidences) dimasukkan kemudian dicocokkan dengan aturan dalam basis pengetahuan untuk memberikan rekomendasi. Model keputusan pemberian rekomendasi pupuk disajikan pada Gambar 2. Pada bagian awal, pengguna akan memasukkan fakta-fakta mengenai fase tanaman (bibit, TBM, atau TM), varietas tanaman, umur tanaman, dan jenis tanah pada lahan (khusus untuk TBM dan TM). Fakta-fakta tersebut, ditambah dengan data kandungan unsur pupuk dapat diolah untuk menghasilkan rekomendasi pupuk secara umum (RPU). Rekomendasi yang diberikan baru sebatas jenis pupuk dan anjuran dosis yang diberikan, khususnya untuk TBM dan TM. Adapun untuk fase bibit, proses ke-1 ini sudah menghasilkan rekomendasi final karena fase bibit tidak memerlukan fakta-fakta lainnya. Rekomendasi tersebut diperoleh dari menggunakan proses runut maju dengan memperhatikan aturan-aturan yang telah disusun berdasarkan studi terhadap sejumlah literatur sekunder dan telah disimpan dalam kode program.

Pada proses ke-2, pengguna akan memasukkan fakta-fakta mengenai defisiensi unsur pada tanah hasil uji tanah dan/atau defisiensi unsur pada tanaman melalui diagnose visual. Input proses ke-2 ini dilakukan jika tersedia data, namun apabila data tidak tersedia, dapat dilanjutkan proses ke-3. Proses kedua ini menghasilkan jenis dan dosis pupuk yang lebih spesifik karena telah memperhatikan data defisiensi unsur pada tanah dan/atau pada tanaman. Proses ke-3 adalah memasukkan fakta curah hujan. Berdasarkan fakta terakhir, dan memperhatikan fakta mengenai sifat antagonis-sinergis unsur dalam pupuk, maka dihasilkan sebuah rekomendasi pemupukan yang meliputi jenis pupuk, dosis pupuk, waktu/urutan dan tatacara pemupukan. 


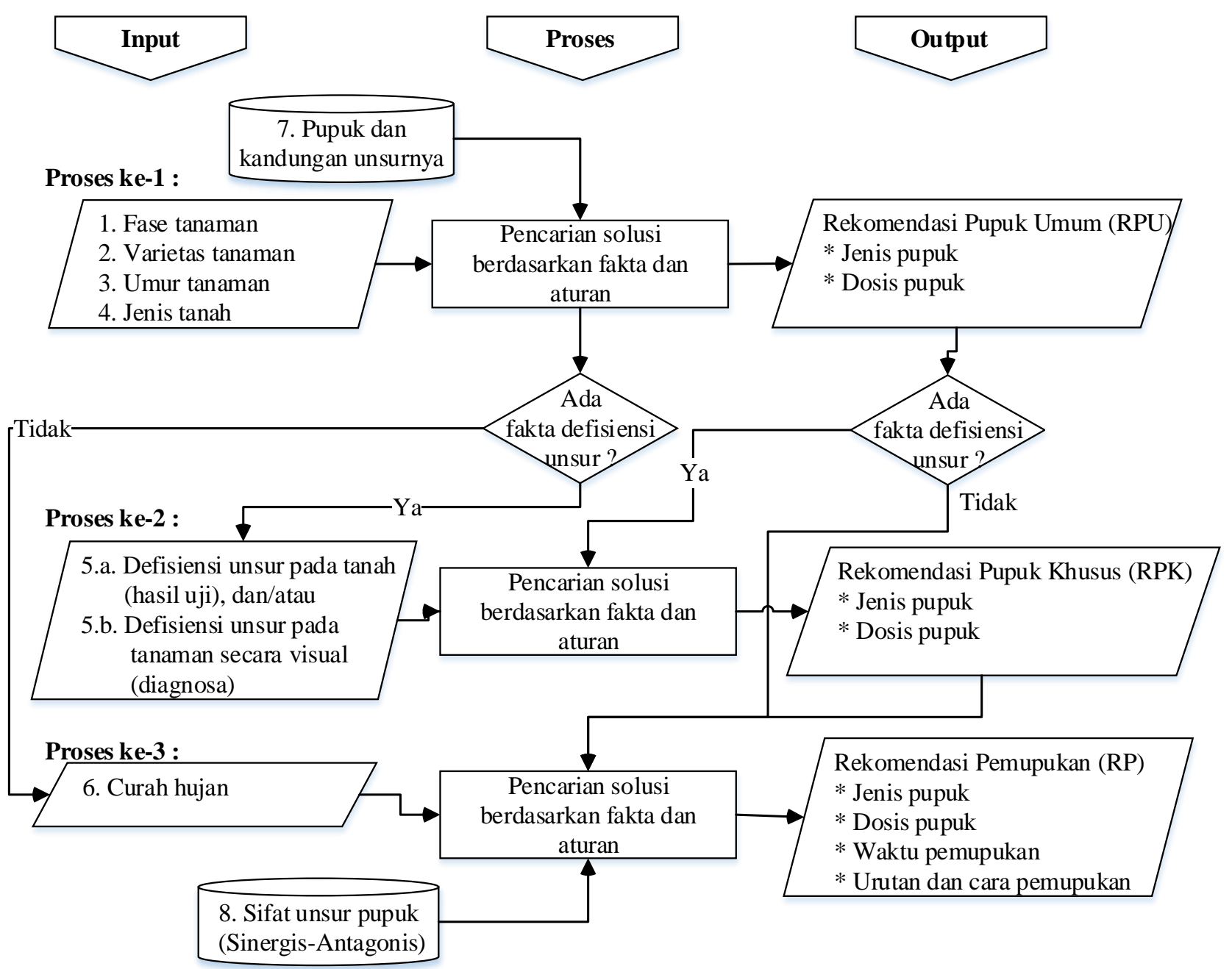

Gambar 2. Model keputusan pemupukan kelapa sawit

Dalam melakukan pencarian runut maju, digunakan teknik pencarian breadth first search. Pencarian dilakukan pada semua node dalam setiap level secara berurutan. Jika pada satu level belum ditemukan solusi, maka pencarian dilanjutkan pada level berikutnya hingga ditemukan solusi. Proses pencarian dilakukan berdasarkan alur proses penalaran seperti pohon keputusan (decision tree).

\subsection{Antarmuka (Interface)}

Antarmuka aplikasi dibuat menggunakan Visual Basic Application (VBA) pada piranti lunak Microsoft Excel. Aplikasi pemupukan kelapa sawit dirancang memiliki kemampuan untuk memberikan rekomendasi pemupukan pada 3 fase tanaman, yaitu bibit, tanaman belum menghasilkan (TBM) dan tanaman menghasilkan (TM). Gambar 3.(a) merupakan tampilan halaman utama dimana pengguna dapat mengkonsultasikan pemupukan pada fase tanaman berupa bibit, TBM atau TM.

Gambar 3.(b) merupakan antarmuka input fakta untuk tanaman pada fase bibit. Pada fase bibit, pengguna hanya diminta memilih varietas tanaman, dan usia bibit. Setelah itu rekomendasi pemupukan untuk bibit dapat diperoleh. Antarmuka hasil rekomendasi pemupukan tanaman kelapa sawit pada fase bibit disajikan pada Gambar 4. Merujuk pada konsep pemupukan yang baik yaitu tepat jenis, tepat dosis, tepat waktu dan tepat cara pemberian, maka rekomendasi memberikan jenis pupuk berupa Rustica 15.15.6.4, dengan dosis 1 gram per bibit, pada waktu hari ketiga paska pembersihan gulma dan diberikan dengan rotasi 2 minggu, serta cara pemberian melalui proses penaburan pupuk pada tepian kantong dan menghindari pemberian pupuk langsung pada tanaman. 


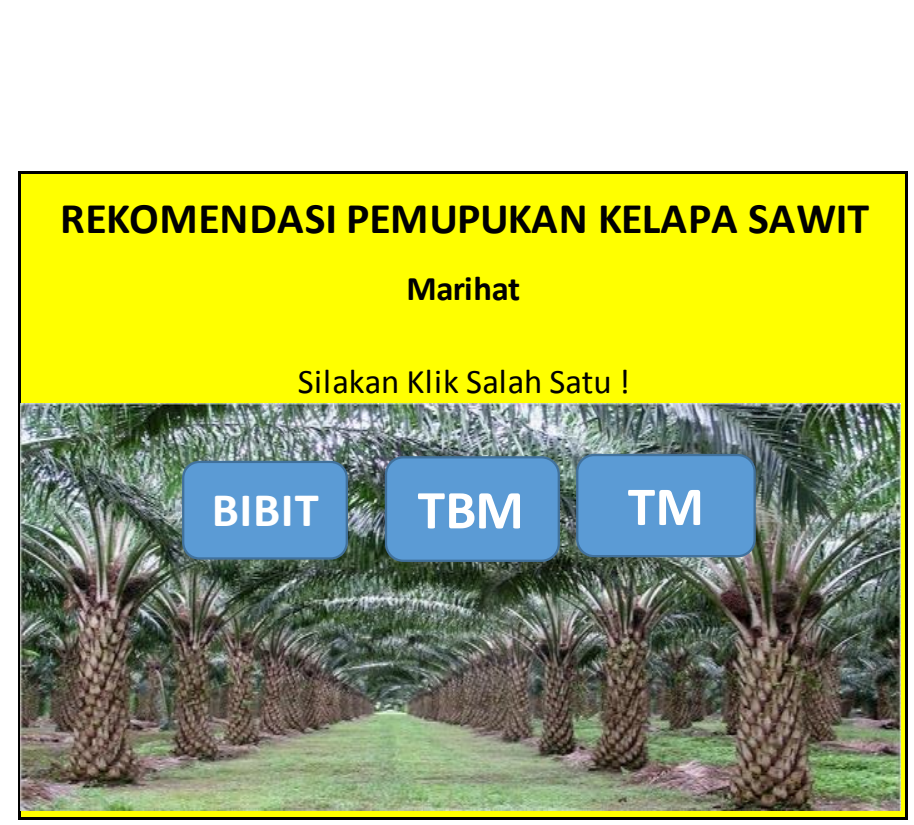

(a)

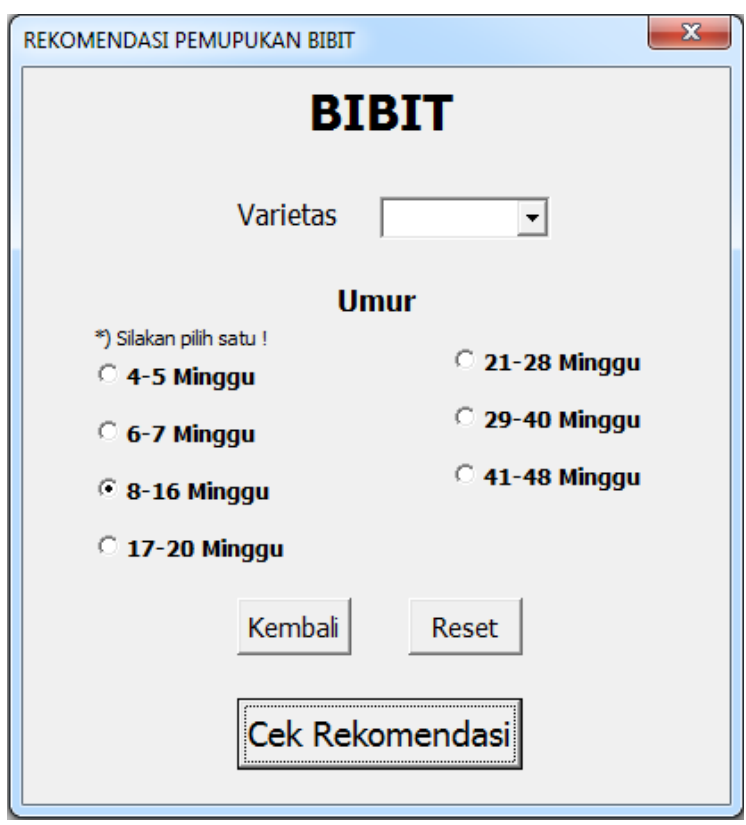

(b)

Gambar 3. Aplikasi rekomendasi pemupukan: (a) Menu utama, (b) Input fakta fase bibit

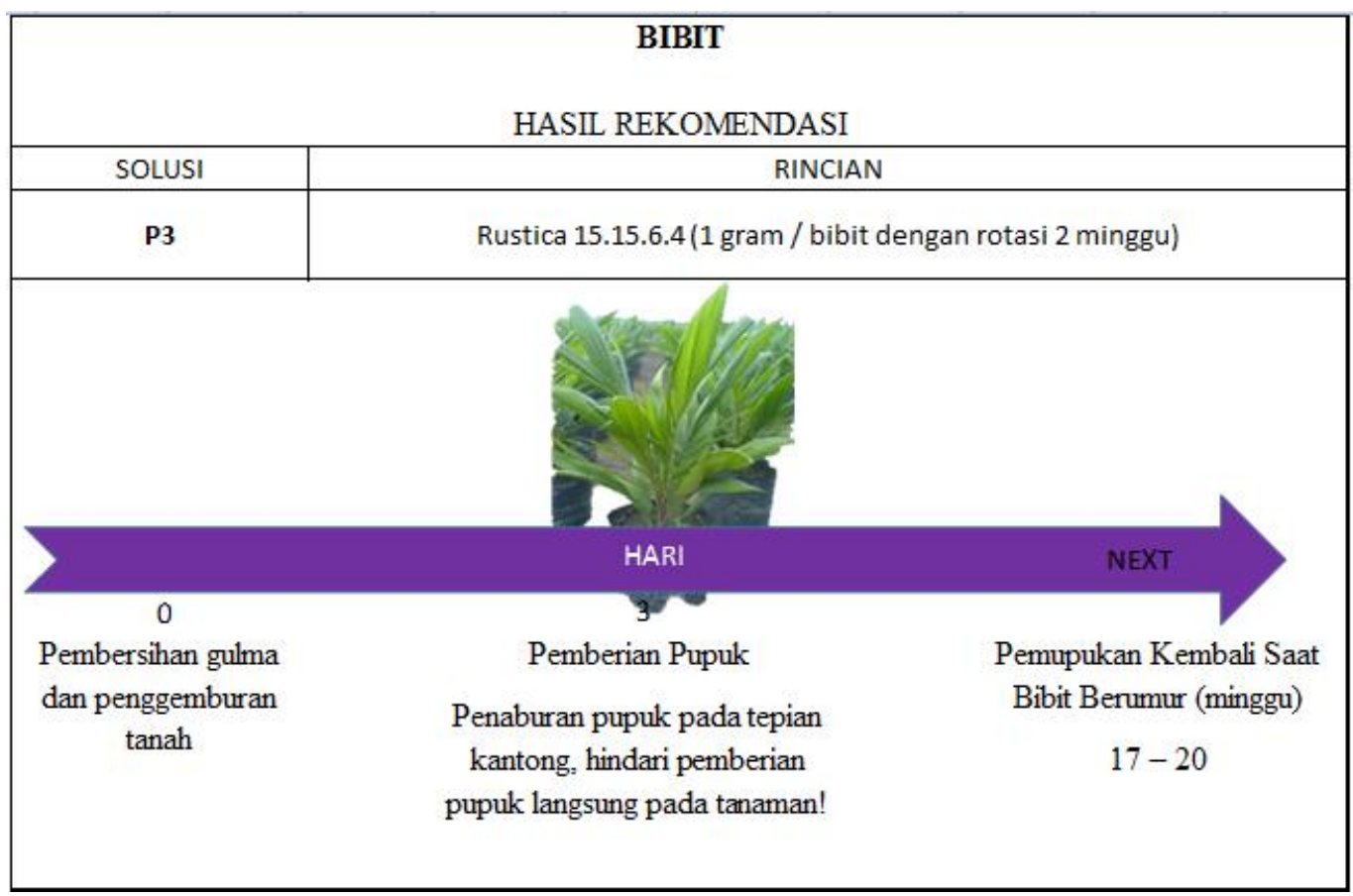

Gambar 4. Hasil rekomendasi pemupukan untuk fase bibit

Selanjutnya, Gambar 5 adalah antarmuka input fakta untuk konsultasi pemupukan tanaman fase TBM. Input fakta untuk TBM adalah varietas tanaman, jenis lahan, usia tanaman, defisiensi unsur pada tanah dan/atau tanaman, dan data curah hujan. Sesuai dengan model keputusan, fakta defisiensi unsur bersifat opsional, jika data tersedia, maka data tersebut dapat dijadikan sebagai input dan sebaliknya jika data tidak tersedia maka dapat dipilih tab "Tidak Ada" pada bagian defisiensi unsur.

Gambar 6 adalah antarmuka hasil rekomendasi pemupukan untuk contoh TBM pada usia sekitra 12 bulan. Berdasarkan informasi hasil, pupuk diberikan pada minggu pertama ada dua jenis yaitu pupuk yang mengandung unsur $\mathrm{N}$ dan unsur $\mathrm{K}$, dimana untuk unsur $\mathrm{N}$ disarankan menggunakan pupuk Za daripada pupuk Urea. Selanjutnya pupuk lainnya diberikan pada minggu kelima, karena hal tersebut telah memperhatikan aspek sinergis-antagonis unsur pada pupuk sebagaimana dianjurkan oleh sumber sekunder (literatur). 


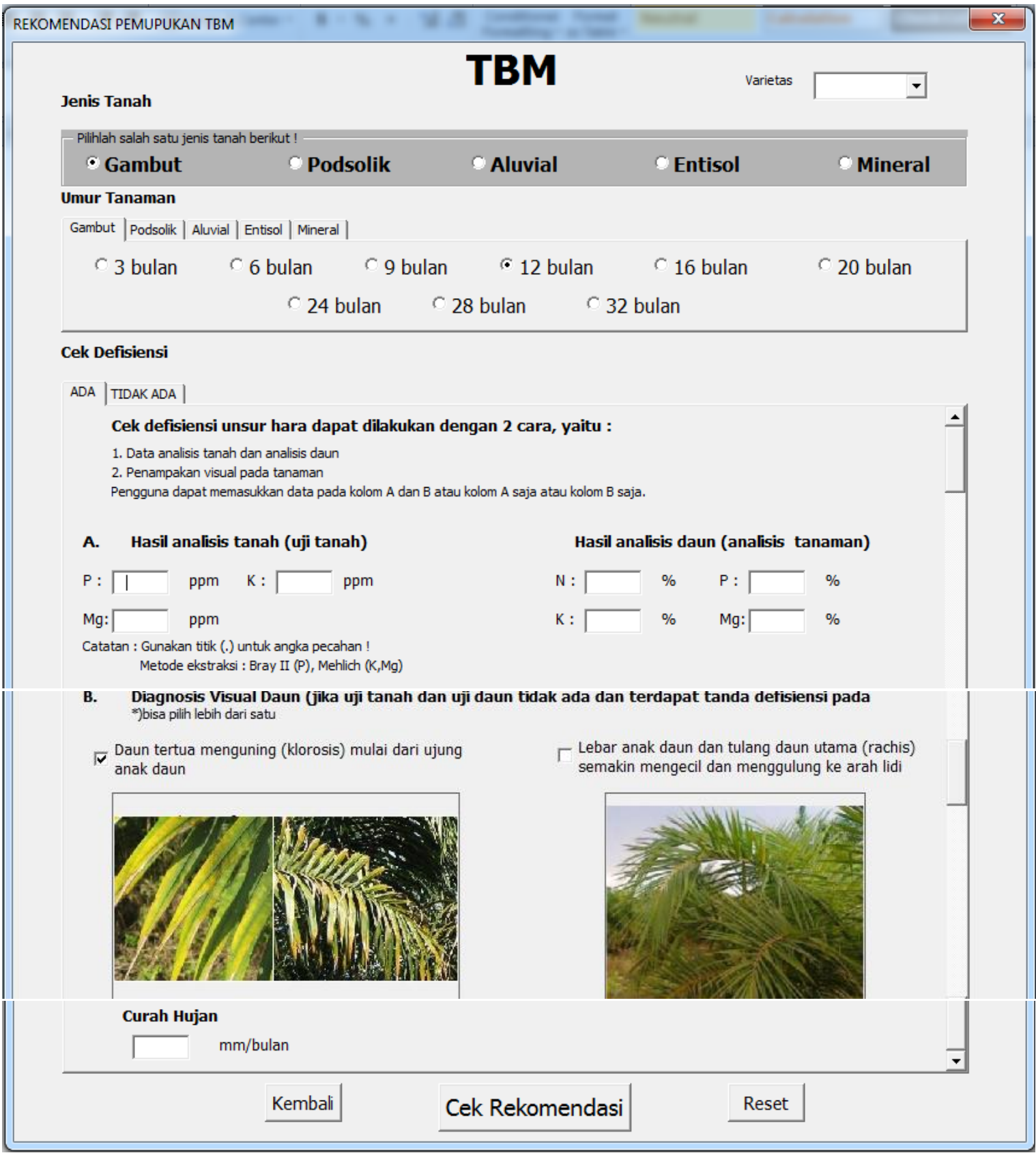

Gambar 5. Input fakta untuk tanaman fase TBM

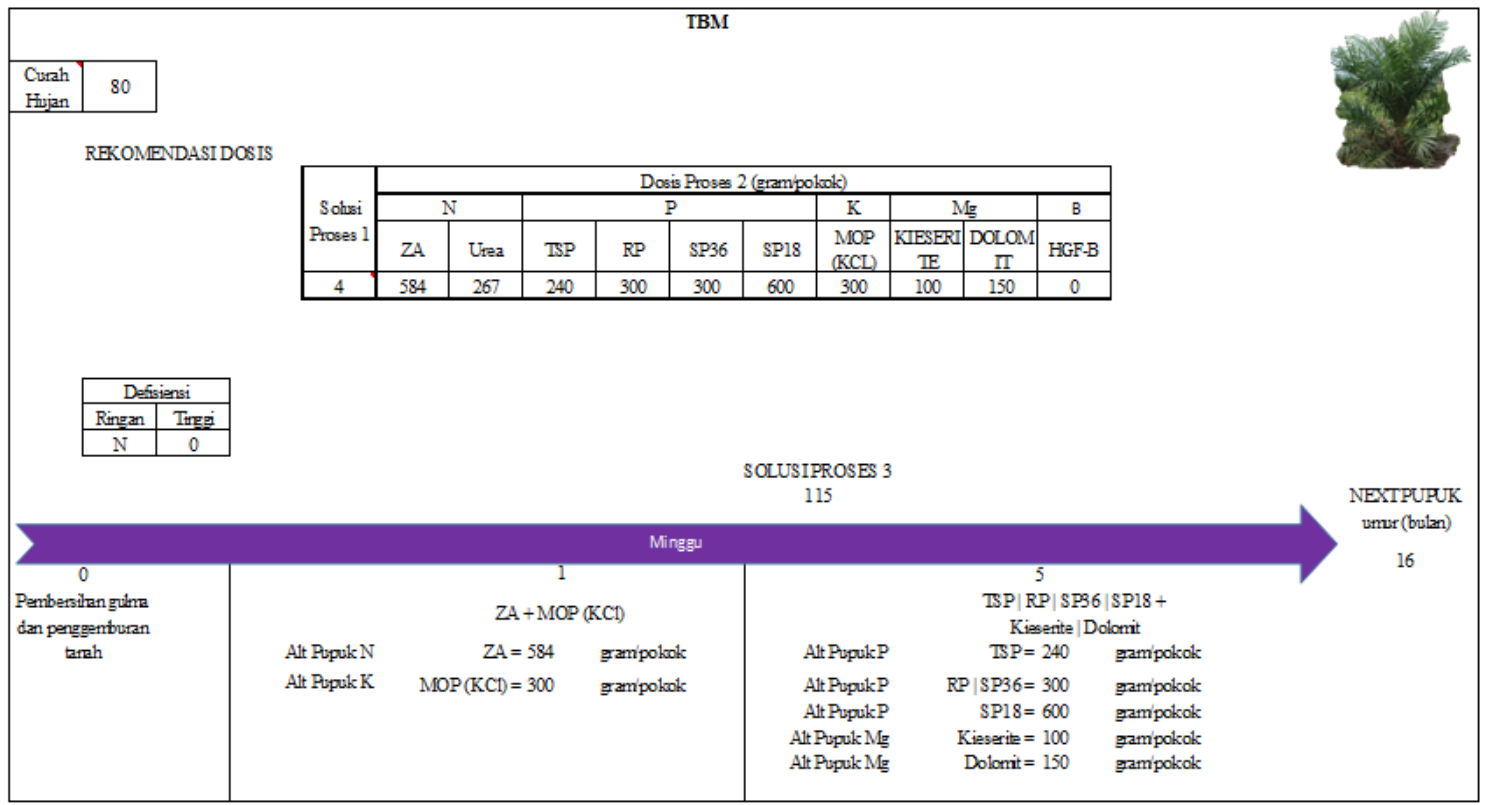

Gambar 6. Hasil rekomendasi pemupukan untuk fase TBM 
Aplikasi sistem pakar rekomendasi pemupukan yang dibuat dicobakan pada salah satu pengguna, pengelola perkebunan rakyat kelapa sawit. Hasil yang diperoleh adalah aplikasi cukup lengkap karena mampu memberikan rekomendasi pemupukan sesuai fase pertumbuhan tanaman kelapa sawit, mulai dari bibit, tanaman belum menghasilkan buah sampai tanaman menghasilkan buah. Hal yang cukup membantu dalam aplikasi ini adalah adanya input fakta mengenai analisis pohon dan daun karena pada lahan perkebunan rakyat yang sedang dalam proses perbaikan, setelah tidak dikelola beberapa waktu, pengelola kebun banyak menemui kondisi pohon-pohon kelapa sawit yang berbeda-beda sebagai indikator adanya defisiensi unsur pada tanaman.

Aplikasi yang dirancang juga memberikan informasi alternatif pupuk yang bisa digunakan oleh pengelola untuk memenuhi kebutuhan suatu unsur. Sebagai contoh, untuk memenuhi kebutuhan unsur N, dapat digunakan pupuk $\mathrm{Za}$ atau Urea. Kemudian penting juga bagi pengguna adalah informasi rekomendasi jadwal (timeline) pelaksanaan pemupukan.

Meskipun secara konsep cukup lengkap, aplikasi sistem pakar ini masih memiliki sejumlah kelemahan. Salah satunya aplikasi ini masih dibangun menggunakan VBA pada aplikasi spreadsheet sehingga hanya bisa digunakan menggunakan perangkat komputer. Aplikasi yang dibuat masih menggunakan data contoh untuk satu varietas tanaman, yaitu Marihat. Kemudian untuk melakukan penambahan fakta dan aturan harus dilakukan oleh knowledge engineer, belum bisa dilakukan oleh pengguna ahli (expert) dalam melakukan penambahan basis pengetahuan dan modifikasi aturan.

\section{Kesimpulan}

Aplikasi sistem pakar rekomendasi pemupukan kelapa sawit menggunakan fakta-fakta berupa varietas tanaman, fase dan umur tanaman, jenis tanah, defisiensi unsur pada tanah dan tanaman, curah hujan, data kandungan pupuk, dan sifat unsur hara (sinergis-antagonis) pada pupuk. Aplikasi yang dibuat mampu memberikan rekomendasi pemupukan dengan melakukan inferensi runut maju (forward chaining) berdasarkan fakta-fakta yang telah disimpan (data-given) dan aturan yang telah dibuat pada basis pengetahuan. Aplikasi yang dibuat menggunakan VBA pada aplikasi spreadsheet dapat membantu pengelola perkebunan rakyat kelapa sawit untuk mengetahui rekomendasi pemupukan pada tanaman Marihat. Aplikasi yang dibuat memerlukan perbaikan dalam mekanisme penyimpanan basis pengetahuan dan modifikasi aturan agar dapat dilakukan oleh pengguna tenaga ahli (expert)

\section{Daftar Pustaka}

Allorerung, D., Syakir, M., Poeloengan, Z., Syafaruddin, \& Rumini, W. (2010). Budidaya Kelapa Sawit. Jakarta: Aska Media.

Arhami, M. (2005). Konsep Dasar Sistem Pakar. Yogyakarta: Andi.

Direktorat Jendral Perkebunan. 2015. Luas Area, Produksi dan Produktivitas Perkebunan di Indonesia Tahun 2011-2015. Jakarta : Direktorat Jendral Perkebunan.

Firmansyah, M. A. 2010. Rekomendasi Pemupukan Umum Karet, Kelapa Sawit, Kopi, dan Kakao (Online), (http://kalteng.litbang.pertanian.go.id/ind/index.php/publikasi-mainmenu-47/artikel/151-rekomendasipemupukan-umum-karet-kelapa-sawit-kopi-dan-kakao, diakses 20 Juli 2016 ).

Foth, H. D. 1994. Dasar-dasar Ilmu Tanah Edisi Keenam. Jakarta: Erlangga.

Hidayat, W. 2012. Manajemen Pemupukan Pada Perkebunan Kelapa Sawit (Elaeis guineensis Jacq.) di Tambusai Estate, PT. Panca Surya Agrindo, First Resources Ltd., Kabupaten Rokan Hulu, Riau. Bogor: IPB.

Krishnamoorthy, C. S., \& Rajeev, S. (1996). Artificial Intelligence and Expert Systems for Engineers. CRC Press: Florida.

Limbong, R. K. 2011. Manajemen Pemupukan Pada Perkebunan Kelapa Sawit (Elaeis guineensis Jacq.) di Gunung Sari Estate, PT. Ladangrumpun Suburabadi, Minamas Plantation, Kabupaten Tanah Bumbu, Kalimantan Selatan. Bogor: IPB.

Lubis, A. U. 2008. Kelapa Sawit (Elaeis guineensis Jacq.) Di Indonesia. Medan: PPKS.

Lumbangaol, P. (2011). Pedoman Pembuatan Dosis Pupuk Kelapa Sawit. Medan: Musim Mas.

Malangyoedo, A. 2014. Sukses Pengelolaan Perkebunan Kelapa Sawit. Yogyakarta: Penerbit Andi.

Pahan, I. 2006. Panduan Lengkap Kelapa Sawit Manajemen Agribisnis Dari Hulu Hingga Hilir. Jakarta: Penebar Swadaya. 
Planck, U. (1990). Sosiologi Pertanian. Jakarta: Yayasan Obor Indonesia.

Rani, P. M., Rajesh, T., \& Saravanan, R. 2011. Expert System in Agriculture : A Review. Journal of Computer Science and Applications, Vol. 3 (1) : 59-71.

Redington, Dana 1999. A Review of Knowledge Engineering and Expert Systems : Towards Expert Operators in Forth. The Journal of Forth Application and Research, Vol. 4 (1) : 85-94.

Salmiyati, Heryansyah, A., Idayu, I., \& Supriyanto, E. 2014. Oil Palm Plantations Management Effects on Productivity Fresh Fruit Bunch (FFB). APCBEE Procedia 8 : 282-286.

Sutejo, M., \& Kartasapoetra. 1990. Pupuk dan Cara Pemupukan. Jakarta: Rineka Cipta.

Syakura, A., Priyandari, Yusuf., \& Zakaria, Roni. 2017. Perancangan Basis Pengetahuan untuk Pengambilan Keputusan Pemupukan pada Perkebunan Kelapa Sawit. Seminar Nasional Teknologi Informasi dan Komunikasi 2017 (SENTIKA 2017), Yogyakarta, 17 - 18 Maret 2017.

Turban, E., Aronson, J. E., \& Lian, T.-P. 2007. Decision Support Systems and Intelligent Systems 7th edition. New Delhi: Prentice-Hall of India.

Ulum, M., \& Hariyanto. 2015. Statistik Kelapa Sawit Indonesia (Indonesian Oil Palm Statistics) 2014. Jakarta: Badan Pusat Statistik.

Urrea, C., Henriquez, G., \& Jamett, M. 2015. Development of An Expert System to Select Materials for The Main Structure of A Transfer Crane Designed for Disable People. Expert System with Aplications 42 : 691-697.

Yuhendra. (2008). Rekayasa Pengetahuan Pakar Berbasis Aturan Untuk Identifikasi Kerusakan Hardware. In Seminar Nasional Informatika 2008 (pp. 295-307). 